\title{
Evaluation of calcaneal enthesophytes in insertional Achilles tendinopathy by radiography and magnetic resonance imaging: intra- and inter-observer reliability
}

\author{
Dário Maciel Silveira Junior ${ }^{1 \mathbb{D}}$, Tiago Soares Baumfeld ${ }^{2} \mathbb{D}$, Daniel Soares Baumfeld ${ }^{2} \mathbb{D}$, Wilel Almeida Benevides ${ }^{1 \mathbb{D}}$, \\ Thiago Alexandre Alves Silva' ${ }^{1}$
}

1. Hospital Madre Teresa, Belo Horizonte, MG, Brazil.

2. Hospital Felício Rocho, Belo Horizonte, MG, Brazil.

\section{Abstract}

Objective: Evaluate intra- and inter-observer variation in the presence of enthesophytes in patients with insertional Achilles tendinopathy on radiographic ( $X$-ray) and magnetic resonance imaging (MRI) images.

Methods: We selected X-ray and MRI images of 20 patients diagnosed with an injury. We sent a questionnaire to five foot and ankle surgeons and five radiologists. We obtained answers about diagnosis accuracy and the presence of insertional enthesophytes (bone spurs).

Results: Intra-observer agreement with regards to diagnosis accuracy in the MRI analysis was a K of 0.77 (0.62 to 1.00 ), while in the $\mathrm{X}$-ray analysis, the $\mathrm{K}$ was 0.95 (0.77 to 1.00). Intra-observer agreement on the presence of enthesophytes in the MRI analysis had a $\mathrm{K}$ coefficient of 0.90 (0.68 to 1.00) and intra-observer agreement in the X-ray of 0.93 (0.86 to 1.00). The evaluation of inter-observer agreement on the diagnosis accuracy had a $\mathrm{K}$ coefficient between 0.09 and 0.20 . Inter-observer agreement regarding the presence of enthesophytes was a $\mathrm{K}$ value between 0.59 and 0.63 for the $\mathrm{MRI}$ and a $\mathrm{K}$ between 0.81 and 0.82 for the $\mathrm{X}$-ray results.

Conclusion: Intra-observer values for diagnosis accuracy of the MRI and X-ray tests indicated strong to almost perfect agreement, similar to the intra-observer values for evaluation of the presence of enthesophytes, but the X-ray had better agreement. In both tests, intra-observer agreement on the presence of osteophytes was weak in comparison to inter-observer agreement, yet in the inter-observer evaluation of the presence of enthesophytes, the X-ray agreement was greater than the MRI values.

Level of Evidence III; Diagnostic Study.

Keywords: Calcaneal tendon; Tendinopathy; Observer variation.

\section{Introduction}

Approximately $6 \%$ of the general population will develop insertional Achilles tendinopathy at some point in life ${ }^{(1)}$. The condition has a bimodal distribution, is more common in athletes, and represents $6-17 \%$ of all injuries in this group. However, it can also be present in middle-aged, overweight patients who are non-athletes and have no history of physical activity ${ }^{(2)}$. There is also a correlation between the condition and seronegative arthropathies ${ }^{(3)}$. Achilles tendinopathy is characterized by pain, functional limitation and swelling around the tendon. It can be classified as an insertional and noninsertional tendinopathy, two distinct pathologies with different pathophysiology and treatment options ${ }^{(4)}$. The middle and insertional portions of the tendon are morphologically, functionally and physiologically different in their normal state. At the onset of the pathology, changes in the cell matrix are indistinguishable and the pathophysiology appears to be
Study performed at the Hospital Madre Teresa, Belo Horizonte, MG, Brazil.

Correspondence: Dário Maciel Silveira Junior. 471 Alberto Bressane St., São Lucas, Belo Horizonte, MG, Brazil, Zip Code: 30240-470. E-mail: dario.msj@hotmail.com Conflicts of interest: none. Source of funding: none. Date received: March 21, 2020. Date accepted: March 22, 2020. Online: April 30, 2020.
How to cite this article: Silveira Junior DM, Baumfeld TS, Baumfeld DS, Benevides WA, Silva TA. Evaluation of calcaneal enthesophytes in insertional Achilles tendinopathy by radiography and magnetic resonance imaging: intra- and inter-observer reliability. J Foot Ankle. 2020;14(1):46-51. 
the same. However, as the lesion develops, the characteristics and treatment options of each one appear different ${ }^{(5)}$.

The essence of tendinopathy is an ineffective tendon repair response, with degeneration and random proliferation of tenocytes, rupture of collagen fibers and subsequent increase in the non-collagenous matrix. In diseased tendon samples, characteristics such as loosening of the fibers and the existence of more wavy fibers are present, with an increase in type III (reparative) collagen ${ }^{(6-8)}$.

The diagnosis of insertional tendinopathy is based mainly on patient history and physical examination. Upon palpation, there is tenderness in the distal $2 \mathrm{~cm}$ of the Achilles tendon, with the presence of swelling and redness in the posterior region of the heel. Tests to assess the limitation of ankle range of motion and to rule out possible contractures and shortening supplement the clinical examination. Patients report pain, which is aggravated by physical activity, and stiffness, especially after prolonged periods of rest ${ }^{(1)}$.

The presence of an enthesophyte in the posterior region of the calcaneus does not confirm the presence of insertional Achilles tendinopathy and is not exclusive to patients with this condition, as it may also be present in asymptomatic patients without foot and ankle diseases. However, the presence of symptoms is more common in patients with the presence of insertional enthesophyte ${ }^{(9)}$. After clinical suspicion, the use of imaging tests helps to confirm the pathology and provides characteristics of the lesion that may influence treatment. Lateral $X$-ray of the calcaneus is an inexpensive and accessible test, and the best radiographic view to assess the insertional region of the Achilles tendon. This test provides information about the bone characteristics of the lesion, such as the size and location of the enthesophyte, bone conformation of the hindfoot joints and associated diseases, such as Haglund's deformity. The availability of MRI has grown over the years, and it has become a routine test at most major centers. It provides three-dimensional information about the location of the insertional enthesophyte and also enables us to study the conditions of soft tissue surrounding the lesion.

We did not find any studies demonstrating the superiority of one method over another in the literature. The aim of this study was to assess intra- and inter-observer agreement for each type of test. Both the diagnosis and the presence of entesophytes were considered in this agreement analysis.

\section{Methods}

This study was approved by the Institutional Review Board and registered on the Plataforma Brazil database under CAAE (Ethics Evaluation Submission Certificate) number: 24716719.1.0000.5127.

All patients received guidance regarding respect for human rights in relation to the research project and signed the Informed Consent Form.

X-ray and MRI images of 20 patients diagnosed with Achilles insertional tendinopathy who attended an appointment between the years 2018 and 2019 at 2 hospitals in Belo Horizonte and were treated by specialist foot and ankle surgeons were evaluated. The inclusion criterion consisted of obtaining all the medical records in addition to X-ray and MRI results.

These patients were assessed, and the tests used in the research project were those carried out before any treatment, whether conservative or surgical, had been established.

A digital questionnaire was sent to 5 foot and ankle surgeons and 5 radiologists specialized in the musculoskeletal system with varying lengths of experience in the area. They were blinded in relation to the patients and test results they evaluated. They analyzed insertional tendinopathy according to the presence or absence of calcaneal enthesophytes, based on the lateral X-ray of the calcaneus and on MRI images. For each MRI test, 2 coronal, 2 sagittal and 2 axial sections were selected in T1- and T2- weighted scans, with a $90^{\circ}$ inclination of the sections in relation to the calcaneus, where we filmed short videos in which it was possible to see the entire thickness of the calcaneus. These videos provided a clearer view of its posterior tuberosity and the insertional portion of the Achilles tendon. The X-ray and MRI images were included in the questionnaire twice, in random order, to enable us to analyze the intra-observer variation and compare the interobserver variation. In the questionnaire, it was not possible to return to any previous question and no previous training was offered to visualize the lesion. The questions were of the multiple-choice type, in which the respondent answered whether or not a posterior calcaneal enthesophyte was present in the test evaluated. In addition to the 2 options for each question, the respondent could check a third option, stating whether those images were inadequate to assess the lesion.

\section{Statistical analysis}

Ten raters and 20 patients participated in this study. Each of the raters evaluated each test (MRI and X-ray) of each patient at two different time points. We used the Fleiss' Kappa, which is a measure used to assess agreement between three or more raters for each of the tests performed (inter-observer variation). Cohen's Kappa, in turn, was used to assess agreement between the two evaluations performed by the same rater (intra-observer variation) $)^{(10,11)}$.

\section{Results}

Imaging test results of 20 patients diagnosed with Achilles insertional tendinopathy and the presence of enthesophytes were evaluated. Eight of these patients (40\%) were female and 12 (60\%) were male. Age ranged from 29 to 77 years (mean age of 49.2 years and standard deviation of 12.5 years). The lesions presented with 11 cases on the left (55\%) and 9 cases (45\%) on the right.

Regarding the diagnosis of the lesion and the presence of enthesophytes, this finding was identified in 13 (65\%) patients and was not identified in 7 (35\%) patients.

Tables 1 to 4 show the assessment of intra-observer agreement for each of the tests used, considering the accuracy of the diagnosis of the lesion and the presence of enthesophytes. 
Table 1. Assessment of intra-observer agreement in relation to the accuracy of the diagnosis of the lesion in the magnetic resonance imaging analysis

\begin{tabular}{|c|c|c|c|c|c|}
\hline \multicolumn{6}{|c|}{ (1 ${ }^{\text {st }}$ assessment $X 2^{\text {nd }}$ assessment) } \\
\hline \multirow{2}{*}{ Rater } & \multirow{2}{*}{$\begin{array}{c}1^{\text {st }} \\
\text { assessment }\end{array}$} & \multicolumn{2}{|c|}{$2^{\text {nd }}$ assessment } & \multirow{2}{*}{$\begin{array}{c}\text { Kappa } \\
\text { Coefficient }\end{array}$} & \multirow{2}{*}{ p } \\
\hline & & Right & Wrong & & \\
\hline \multirow[t]{2}{*}{1} & Right & $17(85.0 \%)$ & $0(0.0 \%)$ & 1.00 & $<0.001$ \\
\hline & Wrong & $0(0.0 \%)$ & $3(15.0 \%)$ & & \\
\hline \multirow[t]{2}{*}{2} & Right & $17(85.0 \%)$ & $0(0.0 \%)$ & 0.77 & $<0.001$ \\
\hline & Wrong & $1(5.0 \%)$ & $2(10.0 \%)$ & & \\
\hline \multirow[t]{2}{*}{3} & Right & $20(100 \%)$ & $0(0.0 \%)$ & -- & -- \\
\hline & Wrong & $0(0.0 \%)$ & $0(0.0 \%)$ & & \\
\hline \multirow[t]{2}{*}{4} & Right & $15(75.0 \%)$ & $\mathrm{O}(0.0 \%)$ & 1.00 & $<0.001$ \\
\hline & Wrong & $0(0.0 \%)$ & $5(25.0 \%)$ & & \\
\hline \multirow[t]{2}{*}{5} & Right & $16(80.0 \%)$ & $2(10.0 \%)$ & 0.62 & $<0.001$ \\
\hline & Wrong & $0(0.0 \%)$ & $2(10.0 \%)$ & & \\
\hline \multirow[t]{2}{*}{6} & Right & $17(85.0 \%)$ & $0(0.0 \%)$ & 0.77 & $<0.001$ \\
\hline & Wrong & $1(5.0 \%)$ & $2(10.0 \%)$ & & \\
\hline \multirow[t]{2}{*}{7} & Right & $19(95.0 \%)$ & $0(0.0 \%)$ & 1.00 & $<0.001$ \\
\hline & Wrong & $0(0.0 \%)$ & $1(5.0 \%)$ & & \\
\hline \multirow[t]{2}{*}{8} & Right & $16(80.0 \%)$ & $1(5.0 \%)$ & 0.83 & $<0.001$ \\
\hline & Wrong & O (0.0\%) & $3(15.0 \%)$ & & \\
\hline \multirow[t]{2}{*}{9} & Right & $17(85.0 \%)$ & $1(5.0 \%)$ & 0.77 & $<0.001$ \\
\hline & Wrong & $0(0.0 \%)$ & $2(10.0 \%)$ & & \\
\hline \multirow[t]{2}{*}{10} & Right & $17(85.0 \%)$ & $2(10.0 \%)$ & $\approx 0.00$ & 0.730 \\
\hline & Wrong & $1(5.0 \%)$ & $0(0.0 \%)$ & & \\
\hline
\end{tabular}

Note: the significance probability refers to Cohen's Kappa coefficient.

Table 3. Assessment of intra-observer agreement in relation to the presence of enthesophytes in the magnetic resonance imaging analysis

\begin{tabular}{|c|c|c|c|c|c|}
\hline \multicolumn{6}{|c|}{ (1 ${ }^{\text {st }}$ assessment $X 2^{\text {nd }}$ assessment) } \\
\hline \multirow{2}{*}{ Rater } & \multirow{2}{*}{$\begin{array}{c}1^{\text {st }} \\
\text { assessment }\end{array}$} & \multicolumn{2}{|c|}{$2^{\text {nd }}$ assessment } & \multirow{2}{*}{$\begin{array}{c}\text { Kappa } \\
\text { Coefficient }\end{array}$} & \multirow{2}{*}{$\mathbf{p}$} \\
\hline & & Absent & Present & & \\
\hline \multirow[t]{2}{*}{1} & Absent & $6(30.0 \%)$ & $0(0.0 \%)$ & 1.00 & $<0.001$ \\
\hline & Present & $0(0.0 \%)$ & $14(70.0 \%)$ & & \\
\hline \multirow[t]{2}{*}{2} & Absent & $8(40.0 \%)$ & $0(0.0 \%)$ & 0.90 & $<0.001$ \\
\hline & Present & $1(5.0 \%)$ & $11(55.0 \%)$ & & \\
\hline \multirow[t]{2}{*}{3} & Absent & $7(35.0 \%)$ & $0(0.0 \%)$ & 1.00 & $<0.001$ \\
\hline & Present & $0(0.0 \%)$ & $13(65.0 \%)$ & & \\
\hline \multirow[t]{2}{*}{4} & Absent & $6(30.0 \%)$ & $0(0.0 \%)$ & 1.00 & $<0.001$ \\
\hline & Present & $0(0.0 \%)$ & $14(70 \%)$ & & \\
\hline \multirow[t]{2}{*}{5} & Absent & $6(30.0 \%)$ & $1(5.0 \%)$ & 0.78 & $<0.001$ \\
\hline & Present & $1(5.0 \%)$ & $12(60.0 \%)$ & & \\
\hline \multirow[t]{2}{*}{6} & Absent & $6(30.0 \%)$ & $\mathrm{O}(0.0 \%)$ & 0.89 & $<0.001$ \\
\hline & Present & $1(5.0 \%)$ & $13(65.0 \%)$ & & \\
\hline \multirow[t]{2}{*}{7} & Absent & $6(30.0 \%)$ & $0(0.0 \%)$ & 1.00 & $<0.001$ \\
\hline & Present & $\mathrm{O}(0.0 \%)$ & $14(70.0 \%)$ & & \\
\hline \multirow[t]{2}{*}{8} & Absent & 5 (25.0\%) & $1(5.0 \%)$ & 0.88 & $<0.001$ \\
\hline & Present & $0(0.0 \%)$ & $14(70.0 \%)$ & & \\
\hline \multirow[t]{2}{*}{9} & Absent & $7(3.5 \%)$ & $0(0.0 \%)$ & 0.89 & $<0.001$ \\
\hline & Present & $1(5.0 \%)$ & $12(60.0 \%)$ & & \\
\hline \multirow[t]{2}{*}{10} & Absent & $6(30.0 \%)$ & $2(10.0 \%)$ & 0.68 & $<0.001$ \\
\hline & Present & $1(5.0 \%)$ & $11(55.0 \%)$ & & \\
\hline
\end{tabular}

Note: the significance probability refers to Cohen's Kappa coefficient.
Table 2. Assessment of intra-observer agreement in relation to the accuracy of the diagnosis of the lesion in the X-ray analysis

\begin{tabular}{|c|c|c|c|c|c|}
\hline \multicolumn{6}{|c|}{ (1st assessment $X 2^{\text {nd }}$ assessment) } \\
\hline \multirow{2}{*}{ Rater } & \multirow{2}{*}{$\begin{array}{c}1^{\text {st }} \\
\text { assessment }\end{array}$} & \multicolumn{2}{|c|}{$2^{\text {nd }}$ assessment } & \multirow{2}{*}{$\begin{array}{c}\text { Kappa } \\
\text { Coefficient }\end{array}$} & \multirow{2}{*}{$\mathbf{p}$} \\
\hline & & Right & Wrong & & \\
\hline \multirow[t]{2}{*}{1} & Right & 19 (95.0\%) & O (0.0\%) & -- & -- \\
\hline & Wrong & $1(5.0 \%)$ & $0(0.0 \%)$ & & \\
\hline \multirow[t]{2}{*}{2} & Right & $17(85.0 \%)$ & $1(5.0 \%)$ & 0.77 & $<0.001$ \\
\hline & Wrong & $0(0.0 \%)$ & $2(10.0 \%)$ & & \\
\hline \multirow[t]{2}{*}{3} & Right & $19(95.0 \%)$ & $0(0.0 \%)$ & -- & -- \\
\hline & Wrong & $1(5.0 \%)$ & $0(0.0 \%)$ & & \\
\hline \multirow[t]{2}{*}{4} & Right & $19(95.0 \%)$ & $0(0.0 \%)$ & 1.00 & $<0.001$ \\
\hline & Wrong & $0(0.0 \%)$ & $1(5.0 \%)$ & & \\
\hline \multirow[t]{2}{*}{5} & Right & $17(85.0 \%)$ & $1(5.0 \%)$ & 0.77 & $<0.001$ \\
\hline & Wrong & $\mathrm{O}(0.0 \%)$ & $2(10.0 \%)$ & & \\
\hline \multirow[t]{2}{*}{6} & Right & $19(95.0 \%)$ & $0(0.0 \%)$ & 1.00 & $<0.001$ \\
\hline & Wrong & $0(0.0 \%)$ & $1(5.0 \%)$ & & \\
\hline \multirow[t]{2}{*}{7} & Right & $19(95.0 \%)$ & $0(0.0 \%)$ & 1.00 & $<0.001$ \\
\hline & Wrong & $\mathrm{O}(0.0 \%)$ & $1(5.0 \%)$ & & \\
\hline \multirow[t]{2}{*}{8} & Right & $20(100.0 \%)$ & O (0.0\%) & -- & -- \\
\hline & Wrong & $\mathrm{O}(0.0 \%)$ & $0(0.0 \%)$ & & \\
\hline \multirow[t]{2}{*}{9} & Right & $19(95.0 \%)$ & $1(5.0 \%)$ & -- & -- \\
\hline & Wrong & $0(0.0 \%)$ & $0(0.0 \%)$ & & \\
\hline \multirow[t]{2}{*}{10} & Right & $19(95.0 \%)$ & $0(0.0 \%)$ & -- & -- \\
\hline & Wrong & $1(5.0 \%)$ & $0(0.0 \%)$ & & \\
\hline
\end{tabular}

Note: the significance probability refers to Cohen's Kappa coefficient.

Table 4. Assessment of intra-observer agreement in relation to the presence of enthesophytes in the $\mathrm{x}$-ray analysis

\begin{tabular}{|c|c|c|c|c|c|}
\hline \multicolumn{6}{|c|}{ (1 ${ }^{\text {st }}$ assessment $X 2^{\text {nd }}$ assessment) } \\
\hline \multirow{2}{*}{ Rater } & \multirow{2}{*}{$\begin{array}{c}1^{\text {st }} \\
\text { assessment }\end{array}$} & \multicolumn{2}{|c|}{$2^{\text {nd }}$ assessment } & \multirow{2}{*}{$\begin{array}{c}\text { Kappa } \\
\text { Coefficient }\end{array}$} & \multirow{2}{*}{$\mathbf{p}$} \\
\hline & & Absent & Present & & \\
\hline \multirow[t]{2}{*}{1} & Absent & $6(30 \%)$ & $\mathrm{O}(\mathrm{O} \%)$ & 0.89 & $<0.001$ \\
\hline & Present & $1(5 \%)$ & $13(65 \%)$ & & \\
\hline \multirow[t]{2}{*}{2} & Absent & $4(20 \%)$ & $1(5 \%)$ & 0.86 & $<0.001$ \\
\hline & Present & $\mathrm{O}(\mathrm{O} \%)$ & $15(75 \%)$ & & \\
\hline \multirow[t]{2}{*}{3} & Absent & $6(30 \%)$ & $\mathrm{O}(\mathrm{O} \%)$ & 0.89 & $<0.001$ \\
\hline & Present & $1(5 \%)$ & $13(65 \%)$ & & \\
\hline \multirow[t]{2}{*}{4} & Absent & $8(40 \%)$ & $\mathrm{O}(\mathrm{O} \%)$ & 1.00 & $<0.001$ \\
\hline & Present & $\mathrm{O}(\mathrm{O} \%)$ & $12(60 \%)$ & & \\
\hline \multirow[t]{2}{*}{5} & Absent & $5(25 \%)$ & $\mathrm{O}(\mathrm{O} \%)$ & 0.88 & $<0.001$ \\
\hline & Present & $1(5 \%)$ & $14(70 \%)$ & & \\
\hline \multirow[t]{2}{*}{6} & Absent & $8(40 \%)$ & O (O\%) & 1.00 & $<0.001$ \\
\hline & Present & $\mathrm{O}(\mathrm{O} \%)$ & $12(60 \%)$ & & \\
\hline \multirow[t]{2}{*}{7} & Absent & $6(30 \%)$ & $\mathrm{O}(\mathrm{O} \%)$ & 1.00 & $<0.001$ \\
\hline & Present & $\mathrm{O}(\mathrm{O} \%)$ & $14(70 \%)$ & & \\
\hline \multirow[t]{2}{*}{8} & Absent & $7(35 \%)$ & $\mathrm{O}(\mathrm{O} \%)$ & 1.00 & $<0.001$ \\
\hline & Present & $\mathrm{O}(\mathrm{O} \%)$ & $13(65 \%)$ & & \\
\hline \multirow[t]{2}{*}{9} & Absent & 7 (35\%) & $\mathrm{O}(\mathrm{O} \%)$ & 0.89 & $<0.001$ \\
\hline & Present & $1(5 \%)$ & 12 (60\%) & & \\
\hline \multirow[t]{2}{*}{10} & Absent & $7(35 \%)$ & $1(5 \%)$ & 0.89 & $<0.001$ \\
\hline & Present & $\mathrm{O}(0 \%)$ & $12(60 \%)$ & & \\
\hline
\end{tabular}

Note: the significance probability refers to Cohen's Kappa coefficient. 
For instance, when evaluating Table 2, we noted that for most of the raters, a strong or almost perfect agreement was observed in relation to the diagnosis accuracy in evaluating the MRI image. It was not possible to calculate the Kappa coefficient for rater 3 , who made an accurate diagnosis in the $1^{\text {st }}$ and $2^{\text {nd }}$ evaluations. Moreover, weak agreement was observed for rater 10, who expressed disagreement in the case of three patients. The analyses for the other graphs are similar.

Figures 1 to 4 and Tables 5 and 6 show the assessment of inter-observer agreement for each of the tests used, considering the accuracy of the diagnosis of the lesion and the presence of enthesophytes.

Regarding the analysis involving diagnosis accuracy, a weak agreement rate was observed in all situations (Table 5 and Figures 1 and 2).

In the analysis involving the presence of enthesophytes, a moderate or strong agreement rate was identified for the MRI results, with almost perfect agreement rates for the $\mathrm{X}$-ray results (Table 6 and Figures 3 and 4).

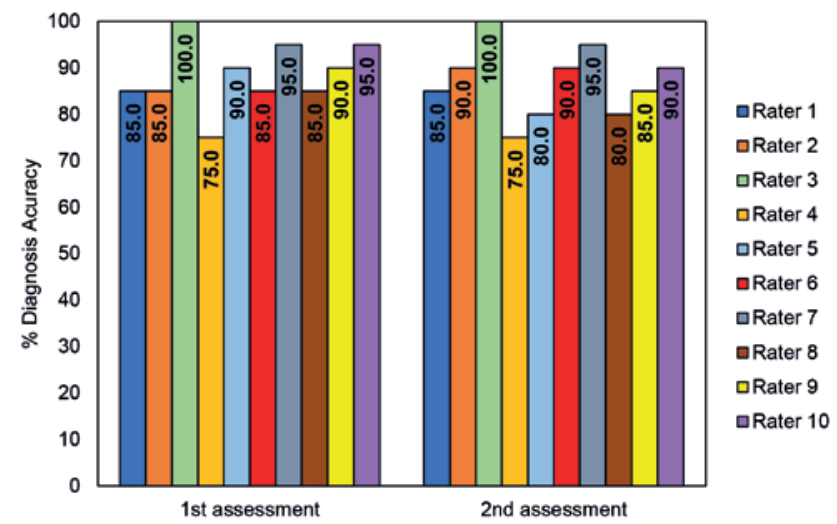

Figure 1. Survey of diagnosis accuracy in the magnetic resonance imaging analysis in the $1^{\text {st }}$ and $2^{\text {nd }}$ assessments.

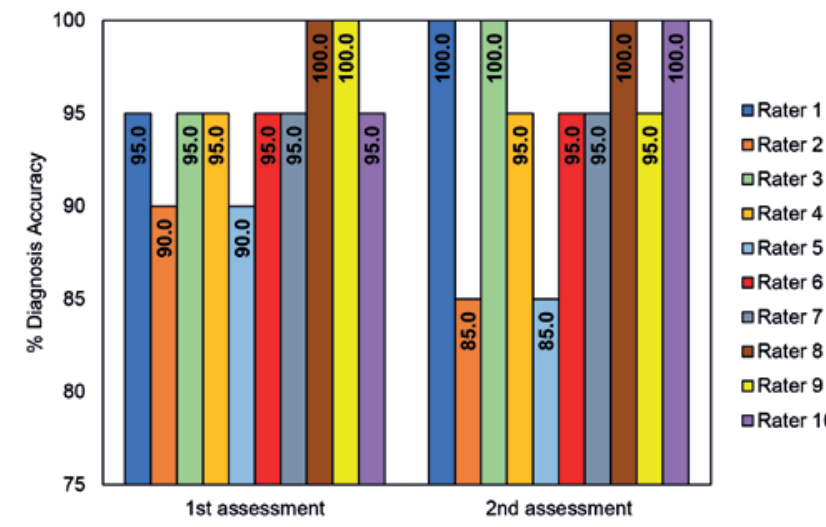

Figure 2. Survey of diagnosis accuracy in the $X$-ray analysis in the $1^{\text {st }}$ and $2^{\text {nd }}$ assessments.

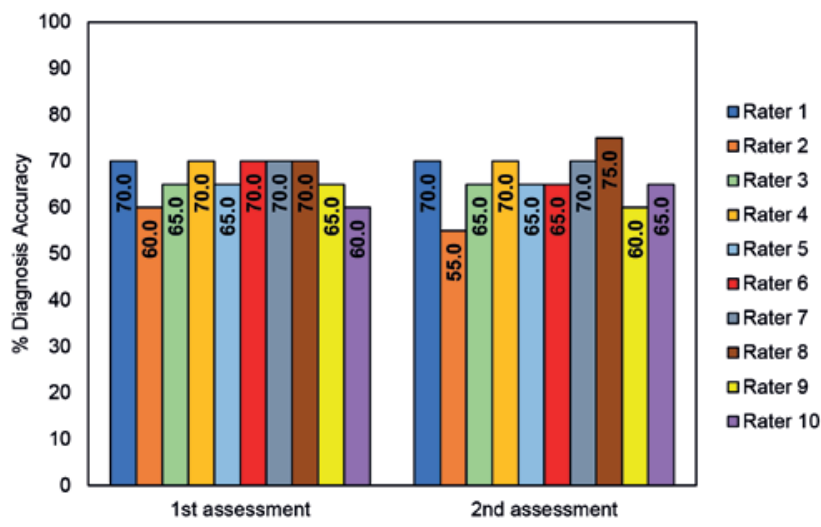

Figure 3. Survey of the presence of enthesophytes in the magnetic resonance imaging analysis in the $1^{\text {st }}$ and $2^{\text {nd }}$ assessments.

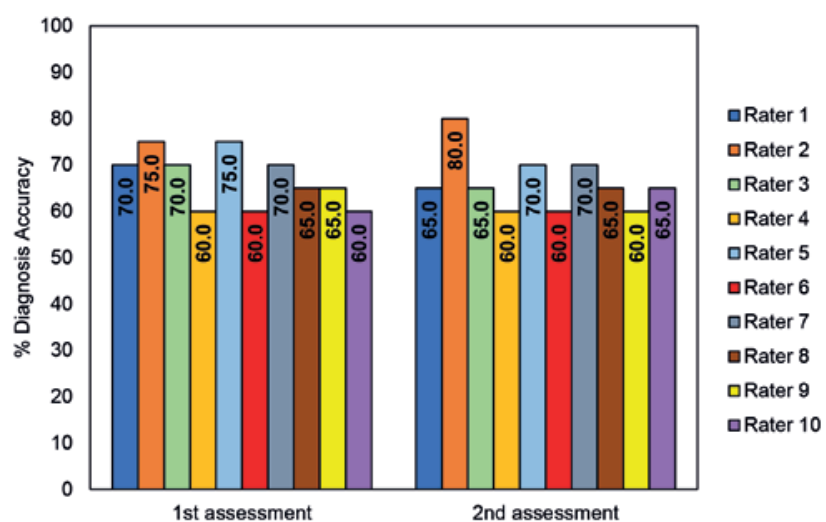

Figure 4. Survey of the presence of enthesophytes in the X-ray analysis in the $1^{\text {st }}$ and $2^{\text {nd }}$ assessments.

Table 5. Assessment of inter-observer agreement in relation to the accuracy of the diagnosis of the lesion considering each type of test and assessment

\begin{tabular}{lccc} 
Type of test & Assessment & Kappa Coefficient & $\mathbf{p}$ \\
\hline MRI & $1^{\text {st }}$ & 0.20 & $<0.001$ \\
& $2^{\text {nd }}$ & 0.17 & $<0.001$ \\
X-ray & $1^{\text {st }}$ & 0.18 & $<0.001$ \\
& $2^{\text {nd }}$ & 0.09 & 0.008 \\
\hline
\end{tabular}

Note: the significance probability refers to Cohen's Kappa coefficient.

Table 6. Assessment of inter-observer agreement in relation to the presence of enthesophytes considering each type of test and assessment

\begin{tabular}{lccc} 
Type of test & Assessment & Kappa Coefficient & $\mathbf{p}$ \\
\hline MRI & $1^{\text {st }}$ & 0.63 & $<0.001$ \\
& $2^{\text {nd }}$ & 0.59 & $<0.001$ \\
X-ray & $1^{\text {st }}$ & 0.82 & $<0.001$ \\
& $2^{\text {nd }}$ & 0.81 & $<0.001$ \\
\hline
\end{tabular}

Note: the significance probability refers to Cohen's Kappa coefficient. 


\section{Discussion}

The diagnosis of insertional Achilles tendinopathy, even in the hands of experienced surgeons, can be challenging. If the patient presents with a painful area upon palpation in the posterior and distal region of the calcaneal tendon, sometimes associated with swelling and hyperemia, a clinical diagnosis of insertional tendinopathy can be suspected( ${ }^{(4)}$.

Imaging tests are routinely used to assist in the diagnosis of insertional Achilles tendinopathy, ruling out differential diagnoses and serving as a guide for surgical scheduling. The presence of abnormalities in imaging tests, such as the presence of calcaneal enthesophytes and tendon enlargement, does not necessarily indicate the presence of clinical disease and vice versa, as demonstrated in the literature in several level II and level IV studies ${ }^{(12,13)}$. The reported percentages of asymptomatic tendons with positive findings for insertional Achilles tendinopathy on imaging tests range from 0\% to 35\%, and the percentages of symptomatic tendons without signs of Achilles tendinopathy on imaging tests range from 0\% to 19\%(12,14-16).

According to Fiamengo et al, the most common associated bone abnormality in insertional Achilles tendinopathy is an enthesophyte at the Achilles insertion in the calcaneus. It is present in about $8.13 \%$ of patients asymptomatic for insertional Achilles tendinitis ${ }^{(17)}$. This enthesophyte generally maintains a normal spinal signal in MRI images and tends to occur mainly at the tendon borders, and not in its central region ${ }^{(18)}$.

Weight-bearing ankle and calcaneus radiography is the most commonly requested test. The anteroposterior view provides information about the presence of any axis deviation, such as varus or valgus deviation. The best view for visualizing the presence of enthesophytes is the lateral view ${ }^{(19)}$. Lateral radiographs of the heel and calcaneus are used to assess the presence and size of enthesophytes, intratendinous calcifications and Haglund's deformity ${ }^{(20)}$.

Regarding MRI, a normal Achilles tendon reveals an average intrasubstance thickness of $6 \mathrm{~mm}$, appearing thicker in tall patients, in men, and in the elderly. In sagittal images, the anterior and posterior margins of the Achilles tendon must be parallel and below the insertion of the soleus. In axial images, the anterior margin of the Achilles is concave for most of its course. In coronal images, the two sides of the Achilles are quite straight, and the tendon widens as it extends distally in the calcaneus ${ }^{(16)}$. MRI tests, in insertional tendinopathy, are often requested in order to assess soft tissues and the characteristics of the lesion in these tissues near the posterior region of the calcaneus, such as degree of tendon degeneration, neovascularization, bursitis and paratendinitis, as well as bone tissues and the implications of the disease in bone, such as bone edema, presence and features of enthesophytes, and intratendinous calcification ${ }^{(9)}$.

In our study, the assessment of intra-observer agreement in relation to the accuracy of the diagnosis of insertional Achilles tendinitis due to the presence of enthesophytes in the MRI analysis, presented a $\mathrm{K}$ value with strong to almost perfect agreement ( $\mathrm{K}$ from 0.62 to 1.00 ), while in the $\mathrm{X}$-ray analysis in relation to diagnosis accuracy, the $\mathrm{K}$ ranged from 0.77 to 1.00 , also showing strong to almost perfect agreement.

The assessment of intra-observer agreement in relation to the presence of enthesophytes in the MRI analysis showed a $\mathrm{k}$ coefficient ranging from 0.68 to 1.00 , and intra-observer agreement on the $\mathrm{X}$-ray ranging from 0.86 to 1.00 , all with statistical significance.

The assessment of inter-observer agreement in relation to the diagnosis accuracy considering each type of test and evaluation had a weak agreement rate in all situations ( $K$ between 0.09 and 0.20). Inter-observer agreement regarding the presence of enthesophytes was identified as having a moderate or strong agreement rate ( $K$ of 0.59 and 0.63 ) for the $\mathrm{MRI}$ results, and almost perfect agreement rates for the $\mathrm{X}$-ray results ( $\mathrm{K}$ of 0.81 and 0.82 ).

The Kappa coefficient is heavily influenced when marginal totals are drastically unbalanced. In these cases, although we observed a high value for overall agreement, we have a low value for the Kappa coefficient. This happened to rater 10 , who presented $85 \%$ (17/20) for overall agreement and a Kappa coefficient close to 0 (zero). If we consider the $1^{\text {st }}$ assessment as a starting point, we have 19 correct diagnoses and only 1 incorrect diagnosis (marginal totals), i.e., very unbalanced marginal totals.

Thus, the results obtained from the analyses involving diagnosis accuracy were influenced by the imbalance of the marginal totals. As regards the results obtained from the analyses involving the actual diagnosis, we observed more balanced marginal totals.

\section{Conclusion}

Our intra-observer values for diagnosis accuracy comparing the MRI and X-ray tests showed a strong to almost perfect agreement, similar to the intra-observer agreement for evaluation of the presence of enthesophytes; however, the $X$-ray showed a greater agreement, ranging from 0.86 to 1.00. In both tests, the agreement was weak when comparing inter-observer agreement on the diagnosis accuracy, yet in the inter-observer assessment for the presence of enthesophytes, the X-ray agreement was greater than the MRI values.

Authors' contributions: Each author contributed individually and significantly to the development of this article: DMSJ *(https://orcid.org/O000-0002-45252768) wrote the article, interpreted the results of the study, participated in the review process; TSB *(https://orcid.org/0000-0001-9244-5194) conceived and planned the activities that led to the study, participated in the review process; DSB *(https://orcid.org/0000-0001-5404-2132) conceived and planned the activities that led to the study, participated in the review process; WAB *(https://orcid.org/0000-0001-6373-1247) conceived and planned the activities that led to the study, participated in the review process, approved the final version; TAAS *(https://orcid.org/0000-0003-2333-2334) conceived and planned the activities that led to the study, participated in the review process, approved the final version. ${ }^{*}$ ORCID (Open Researcher and Contributor ID) (iD). 


\section{References}

1. Chimenti RL, Cychosz CC, Hall MM, Phisitkul P. Current concepts review update: insertional achilles tendinopathy. Foot Ankle Int. 2017;38(10):1160-9.

2. McLauchlan GJ, Handoll HH. Interventions for treating acute and chronic Achilles tendinitis. Cochrane Database Syst Rev. 2001; (2):CDOOO232.

3. Ames PR, Longo UG, Denaro V, Maffulli N. Achilles tendon problems: not just an orthopaedic issue. Disabil Rehabil. 2008; 30(20-22):1646-50

4. Maffulli N, Longo UG, Kadakia A, Spiezia F. Achilles tendinopathy Foot Ankle Surg. 2019 Apr 18. pii: S1268-7731(19)30052-9.

5. Cook JL, Purdam CR. Is tendon pathology a continuum? A pathology model to explain the clinical presentation of loadinduced tendinopathy. Br J Sports Med. 2009;43(6):409-16.

6. Kannus P, Józsa L. Histopathological changes preceding spontaneous rupture of a tendon. A controlled study of 891 patients. J Bone Joint Surg Am. 1991;73(10):1507-25.

7. Fredberg $U$, Stengaard-Pedersen K. Chronic tendinopathy tissue pathology, pain mechanisms, and etiology with a special focus on inflammation. Scand J Med Sci Sports. 2008;18(1):3-15.

8. Longo UG, Ronga M, Maffulli N. Achilles tendinopathy. Sports Med Arthrosc Rev. 2009;17(2):112-26.

9. Chimenti RL, Chimenti PC, Buckley MR, Houck JR, Flemister AS. Utility of ultrasound for imaging osteophytes in patients with insertional achilles tendinopathy. Arch Phys Med Rehabil. 2016;97(7):1206-9.

10. Fleiss JL, Levin B, Paik MC. Statistical methods for rates and proportions. New York: John Wiley \& Sons; 2003.

11. Bloch DA, Kraemer HC. $2 \times 2$ kappa coecients: measures of agreement or association. Biometrics. 1989; 45:269-87.
12. Bakkegaard $M$, Johannsen FE, Højgaard $B$, Langberg $H$ Ultrasonography as a prognostic and objective parameter in Achilles tendinopathy: a prospective observational study. Eur J Radiol. 2015;84(3):458-62.

13. de Jonge S, Tol JL, Weir A, Waarsing JH, Verhaar JA, de Vos RJ. The tendon structure returns to asymptomatic values in nonoperatively treated achilles tendinopathy but is not associated with symptoms: a prospective study. Am J Sports Med. 2015 43(12):2950-8.

14. De Zordo T, Chhem R, Smekal V, Feuchtner G, Reindl M, Fink $C$, et al. Real-time sonoelastography: findings in patients with symptomatic achilles tendons and comparison to healthy volunteers. Ultraschall Med. 2010;31(4):394-400.

15. Fischer MA, Pfirrmann CW, Espinosa N, Raptis DA, Buck FM Dixon-based MRI for assessment of muscle-fat content in phantoms, healthy volunteers and patients with achillodynia: comparison to visual assessment of calf muscle quality. Eur Radiol. 2014;24(6):1366-75.

16. Shaikh Z, Perry M, Morrissey D, Ahmad M, Del Buono A, Maffulli $\mathrm{N}$. Achilles tendinopathy in club runners. Int J Sports Med. 2012;33(5):390-4.

17. Fiamengo SA, Warren RF, Marshall JL, Vigorita VT, Hersh A Posterior heel pain associated with a calcaneal step and Achilles tendon calcification. Clin Orthop Relat Res. 1982;(167):203-11.

18. Schweitzer ME, Karasick D. MR imaging of disorders of the achilles tendon. AJR Am J Roentgenol. 2000;175(3):613-25

19. Irwin TA. Current concepts review: insertional achilles tendinopathy. Foot Ankle Int. 2010;31(10):933-9.

20. van Sterkenburg MN, Muller B, Maas M, Sierevelt IN, van Dijk $\mathrm{CN}$. Appearance of the weight-bearing lateral radiograph in retrocalcaneal bursitis. Acta Orthop. 2010;81(3):387-90. 